\section{THU0015 \\ VARIATION IN MACROPHAGES DIFFERENTIATION AND SREBF1 EXPRESSION BETWEEN INFRAPATELLAR FAT PAD AND SUBCUTANEOUS TISSUES FROM RHEUMATOID ARTHRITIS AND OSTEOARTHRITIS PATIENTS}

Shuhe $\mathrm{Ma}^{1}$, Kosaku Murakami ${ }^{1}$, Motomu Hashimoto ${ }^{2}$, Masao Tanaka ${ }^{2}$, Koichi Murata ${ }^{2}$, Kohei Nishitani ${ }^{2}$, Hiromu Ito $^{3}$, Tsuneyo Mimori ${ }^{1} .{ }^{1}$ Kyoto University Graduate School of Medicine, Dept. of Rheumatology and Clinical and Immunology, Kyoto, Japan; ${ }^{2}$ Kyoto University Graduate School of Medicine, Advanced Medicine of Rheumatic Disease, Kyoto, Japan; ${ }^{3}$ Kyoto University Graduate School of Medicine, Dept. of Orthopedic Surgery, Kyoto, Japan

Background: Sterol regulatory element-binding protein 1 (SREBP1) has been known to upregulate the expression levels of regulators of $\omega-3$ fatty acids in the resolution phase of macrophages, and this would in turn repress the production of pro-inflammatory cytokines. ${ }^{[1,}{ }^{2]}$ In OA joints, adipocytes might participate in inflammatory process. ${ }^{[3]}$ We are interested in the proportion of M1 and M2 macrophages in stromal vascular fraction (SVF) from both tissues in both diseases. And to investigate how srebf1 works in infrapatellar fat pad (IFP, or Hoffa) or subcutaneous (SC) tissue, we studied the expression levels of srebf1, pro-inflammatory cytokines and regulators of fatty acids.

Objectives: To investigate the proportion of CD14 positive cells as well as M1 and M2 macrophages in SVF of Hoffa and SC; and to explore contribution of SREBP1 to rheumatic disease pathological processes of RA and OA.

Methods: After treated with collagenase, macrophages (CD14 positive cells) in SVF were counted by flow cytometry. Then they were divided, half for calculating the ratio between $\mathrm{CD} 80$ positive cells (M1 macrophages) and CD163 positive cells (M2 macrophages), and half for performing QRT-PCR.

Results: Characteristics of the patients

Table 1. Characteristics of the patients

\begin{tabular}{|c|c|c|c|}
\hline & $O A(n=7)$ & $\mathrm{RA}(\mathrm{n}=8)$ & $p$ value \\
\hline Age (years) & $72(62-79)$ & $63(49-76)$ & 0.055 \\
\hline Female patients $(n)$ & 6 & 7 & \\
\hline Male patients (n) & 1 & 1 & \\
\hline Height $(\mathrm{cm})$ & $155(151-164)$ & $157(147-161)$ & 0.341 \\
\hline Body weight $(\mathrm{kg})$ & $62.7(48.7-74.1)$ & $58.7(48.8-72.2)$ & 0.386 \\
\hline pre-ope CRP (mg/L) & $0.75(0-2)$ & $12.8(0-17)$ & 0.064 \\
\hline Underweight & $0 \%$ & $0 \%$ & \\
\hline Normal & $42.9 \%$ & $50.0 \%$ & 0.234 \\
\hline Overweight & $42.9 \%$ & $37.5 \%$ & 0.05 \\
\hline Obese & $14.3 \%$ & $12.5 \%$ & \\
\hline
\end{tabular}

OA: osteoarthritis; RA: rheumatoid arthritis; CRP: C-reactive protein; BMI: body mass index; BMI: <18,5 underweight; BMI: 18.5-24.99 normal; BMI: 25.0-29.99 overweight; $\mathrm{BMI}>30.0$ obesity ${ }^{[4]}$

More CD14 positive cells exist in Hoffa comparing to SC, and M2 macrophages show higher proportion.

A comparison of proportion of CD14 positive cells between Hoffa and SC showed significance both from $\mathrm{OA}$ and from RA. To M2 macrophages proportion, higher percentages of $M 2$ macrophages (OA: $26.3 \pm 5.5 \%$, RA: $22.5 \pm 2.4 \%$ ) exist in Hoffa from both $\mathrm{OA}$ and RA patients, but no significance was found between the diseases. However, the proportion of M1 macrophages (OA: $15.6 \pm 1.7 \%$, RA: $11.3 \pm 2.1 \%$ ) indicated significance.
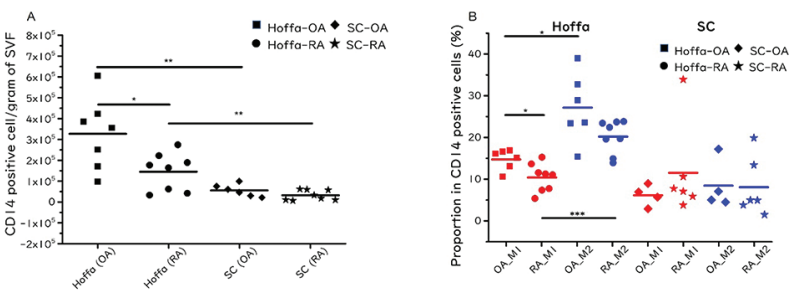

Abstract THU0015 Figure 1. (A) Proportion of CD14 positive cells per gram of SVF from $\mathrm{OA}$ and RA patients. (B) Proportion of M1 and M2 macrophages in CD14 positive cells from OA and RA patients. $\left({ }^{\star} p<0.05,{ }^{* *} p<0.01,{ }^{* * *} p<0.001\right.$, as determined by One-Way ANOVA.)

Srebf1 expressed less in Hoffa than in SC
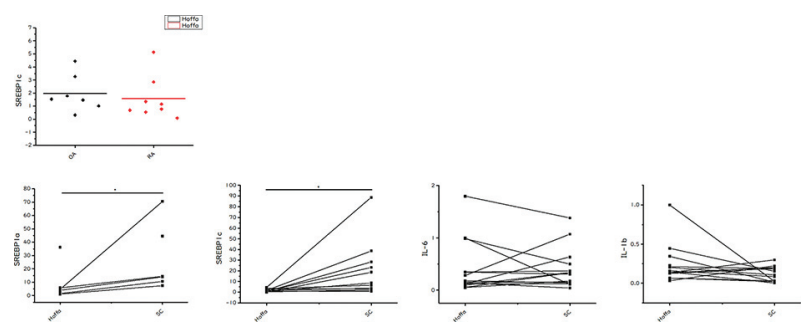

Abstract THU0015 Figure 2. qRT-PCR analysis of cytokine and srebf1 expression levels displayed among total patients. $\left({ }^{*} \mathrm{p}<0.05\right.$, as determined by One-Way ANOVA.)

Results show that in Hoffa, srebf1c expressed less in RA patients than that in $O A$ patients, but no significance was indicated. In the comparison of expression levels between Hoffa and SC, both srebfla and srebf1c showed significance, and more $I L-6$ and $I L-1 \beta$ expressed in Hoffa than in SC.

Conclusion: In RA patients, more M2 macrophages exist in Hoffa than in SC. Lower expression levels of srebf1c in Hoffa from RA patients suggests that macrophages differentiation can be reprogrammed by fatty acid metabolism.

\section{REFERENCES:}

[1] Oishi, Y., et al., Cell Metab, 2017. 25(2): p. 412-427

[2] Shimano, H. and R. Sato, Nat Rev Endocrinol, 2017. 13(12): p. 710-730.

[3] Shimano, H., et al., The Journal of Clinical Investigation, 1997. 99(5): p. 846-854.

[4] Plebanczyk, M., et al., Inflammation, 2018.

Disclosure of Interests: Shuhe Ma: None declared, Kosaku Murakami: None declared, Motomu Hashimoto Grant/research support from: Astellas, Brystol-Meyers, Eisai, Employee of: M. H. is affiliated with the department (Department of Advanced Medicine for Rheumatic Diseases, Kyoto University), which is financially supported by four pharmaceutical companies (Tanabe-Mitsubishi, Chugai, Ayumi, UCB Japan), Speakers bureau: Tanabe Mitsubishi, Brystol-Meyers, Masao Tanaka: None declared, Koichi Murata: None declared, Kohei Nishitani: None declared, Hiromu Ito: None declared, Tsuneyo Mimori: None declared DOI: 10.1136/annrheumdis-2019-eular.460

\section{THU0016 ALTERED EXPRESSION AND FUNCTION OF P2X7 RECEPTOR IN PATIENTSAFFECTED BY SYSTEMIC LUPUS ERYTHEMATOSUS (SLE)}

Anna Lisa Giuliani ${ }^{1}$, Federica Furini ${ }^{2}$, Alessandra Bortoluzzi ${ }^{2}$, Marcello Govoni ${ }^{2}$, Francesco DI Virgilio'. ' University of Ferrara, Morphology, Surgery and Experimental Medicine, Ferrara, Italy, ${ }^{2}$ University of Ferrara, Medical Science, Ferrara, Italy

Background: Extracellular ATP (eATP) is one of the most diffuse danger associated molecular patterns (DAMPs) released actively through specific mechanisms from intact cells, or passively from damaged or dying cells ${ }^{1}$. An implication for eATP has been found in SLE$^{2}$. Among receptors for eATP, P2X7R is deeply involved in inflammatory and immune processes and its activation drives different intracellular pathways such as NLRP3 inflammasome activation, IL- $1 \beta$ maturation and release, IL-6 and TNF- $\alpha$ production, regulation of lymphocyte proliferation and cell apoptosis ${ }^{3}$. Previous studies pointed out a possible relationship between P2X7R signaling pathways and SLE pathogenesis ${ }^{4}$. A marked inflammatory condition characterize serositis, that are among the most common manifestations of SLE, and chloroquine is one of the main drugs employed.

Objectives: The aim of this study was to investigate P2X7R expression and activity in SLE.

Methods: 48 SLE patients, and 20 healthy control $(\mathrm{HC})$ subjects were enrolled. Among SLE patients, 16 (SLE-S) presented, and 32 (SLE-NS) did not present history of serositis. All subjects gave written informed consent to peripheral venous blood withdrawal after approval by the local ethic committee. Plasma samples were used to measure IL-1 $\beta$, IL-6 and TNF- $\alpha$ levels by ELISA. Mononuclear cells were isolated from blood samples by Ficoll gradient sedimentation and employed as follow: i) assessment of IL-1 $\beta, \quad \mathrm{LL}-6$ and $\mathrm{TNF}-\alpha$ release after stimulation with lipopolysaccharide (LPS) and/or Benzoyl ATP (BzATP); ii) evaluation of P2X7R mRNA expression by RT-PCR; iii) measurement of P2X7R activity as BzATP-induced increase of intracellular $\mathrm{Ca}^{2+}$ concentration using the Fura2/AM probe. 